\title{
Measurement methods of building structures deflections
}

\author{
Magdalena Wróblewska ${ }^{1, *}$ \\ ${ }^{1}$ Silesian University of Technology, Faculty of Civil Engineering, Department of Geotechnics \\ and Roads, Gliwice, Poland
}

\begin{abstract}
Underground mining exploitation is leading to the occurrence of deformations manifested by, in particular, sloping terrain. The structures situated on the deforming subsoil are subject to uneven subsidence which is leading in consequence to their deflection. Before a building rectification process takes place by, e.g. uneven raising, the structure's deflection direction and value is determined so that the structure is restored to its vertical position as a result of the undertaken remedial measures. Deflection can be determined by applying classical as well as modern measurement techniques. The article presents examples of measurement methods used considering the measured elements of building structures' constructions and field measurements. Moreover, for a given example of a mining area, the existing deflections of buildings were compared with mining terrain sloping.
\end{abstract}

Keywords: deflected buildings, measurement methods, surface deformation

\section{Introduction}

Vertically deflected structures pose a serious problem in the social and technical context for building engineers at the stage of building rectification. In addition, for mining areas, where deflection values are substantial, this phenomenon is also becoming a part of financial burdens for a mining enterprise because relevant compensation has to be paid or rectification costs covered.

A deflection is a damage affecting the use of a structure. Investigations aimed at identifying users' response to building deflection were carried out, among others, under the works [1]. It was observed in the undertaken investigations that the use of a structure is becoming more difficult with the deflection value starting already from $10 \%$. Vertically deflected structures are additionally exposed to the change in the system of internal forces, which - for significant deflection values - affects structural safety. The permitted deflections of buildings on a mining area were analysed thoroughly in [2] due to the conditions of ultimate load-carrying limit states [2].

* Corresponding author: magdalena.wroblewska@polsl.p1 
Straightening by uneven raising is a commonly applied method [3]. In such case, it is necessary to determine the adequate deflection value, considered as an input value, so as to have a structure brought to the vertical position as a result of rectification. Appropriate verticality measurement methods are employed before and after straightening, as part of a post-execution measurement, to determine the deflection value and direction. Admissible deviations in structure execution have to be known to interpret the data obtained correctly. A difference in the depth of foundations, causing building deflection of up to $3 \mathrm{~mm} / \mathrm{m}$, is permitted already at the stage of foundation design [4]. If the tolerances permitted for construction of certain structural elements determined based on standards and technical guidelines are exceeded, the accuracy of building structure execution is seriously questioned [5].

A deflection of building structures, considered as a mining damage, is reflected in the loss of the structures' value. By juxtaposing the methods applied to determine a relationship between the building deflection magnitude and the size of the damage [6], a new formula was started to be applied, based on the assumption that with each next per mille of building deflection, its incremental loss value is rising by a certain constant value.

Mining impacts on the deflected buildings, in form of land curvatures and horizontal deflections, cause the deformation of particular structural elements, as a result of which the deflection of walls is not always identical as the sloping of floors. The additional strains, formed this way, may have a negative impact on the structure's technical condition and safety [7]. Due to such differentiated values of deflection for particular structural elements of the building, a specific value and direction of structure deflection have to be determined, especially for those structures undergoing a straightening process [8].

\section{Measurement methods of building structures displacements}

Considering the measurement methods of building structures displacements, methods can be distinguished consisting of altimetric survey or topographical survey. In order to obtain absolute values, a measurement made has to be referred to fixed (main) points situated outside the impacts of exploitation. However, measurement often consists of determination of absolute values as there are no fixed points in the adjacency of the building. Such situations take place mainly on areas with a large number of parcels used, where the reach of the impact covers extensive areas. The number and manner of arranging controlled points on the studied structure should ensure the possibility of obtaining a full picture of the structure deformation course [9]. Intervals between measurements, i.e. measurements appropriately planned in time, allow to observe a condition of the building in the given phases of the depression basin course.

Data about deflections is collected on the basis of field measurements. The appropriate method is chosen, among others, depending on the expected accuracy, availability of equipment, software and time, availability of measurement points and visibility. The methods encompass classical measurements where distance, angles and height difference between points is measured directly, and modern methods using satellite techniques, photogrammetry and laser scanning. As technology is advancing, the automation of geodesic measurements has also been seen, including telemetric methods, the example of which can be a laser sensor of building vibrations and deflections [10].

The article presents building measurement methods for determining the deflection of structural elements, in particular walls, floors and terrain sloping measurement. 


\subsection{Registration of wall deflections}

\subsubsection{Levelling measurements}

The deflections of buildings in field should be determined by means of geodesic levelling techniques by measuring the depression of the benchmarks situated on the building base level [1] (Fig. 1). Precise or technical direct levelling can be distinguished for the commonly used methods. It is very often seen in field that only single controlled points are stabilised, which provides an incomplete view of building displacement. It is therefore recommended to establish at least four controlled points in the corners of the structure [11]. In practice, this only takes place for large structures such as industrial buildings or churches.

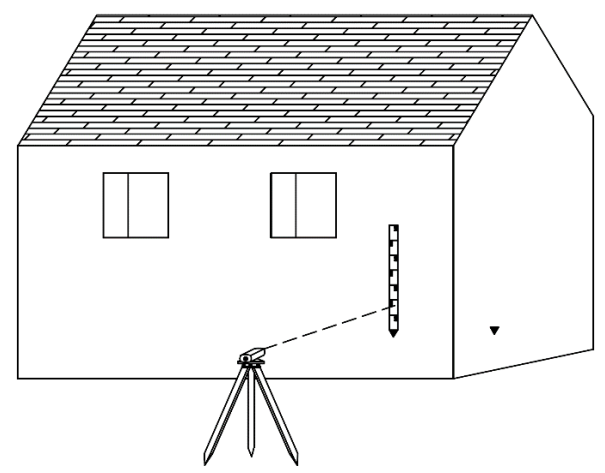

Fig. 1 Levelling measurement of benchmarks.

\subsubsection{Direct measurements of deflections}

It is often, however, impossible to stabilise observation points, and other measurement methods have to be employed such as the method of direct projection on the levelling rod (Fig. 2). Verticality measurement, consisting of rectilinear projection of characteristic points of each wall corner on the rule, next to the classical levelling of benchmarks, is the method most often used in practice by measurement and geological teams of mining companies. Wall verticality measurement can be obtained directly and rapidly using an electronic spirit level used in construction practice. It is quite problematic in this method to determine the application point, especially for building walls undergoing substantial deformations.

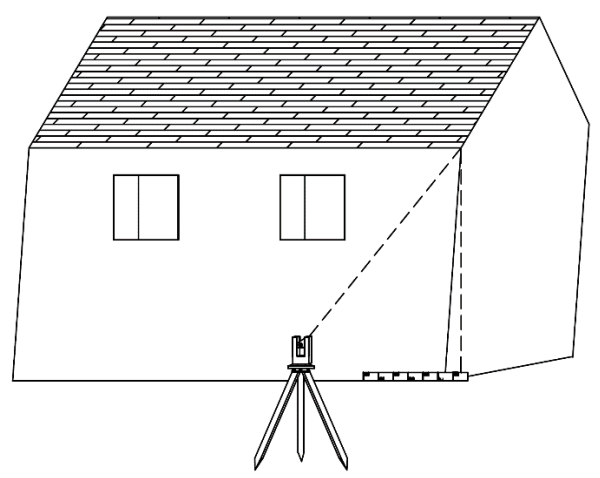

Fig. 2 Method of direct projection on the levelling rod. 


\subsection{Registration of floor sloping}

The majority of methods of measuring the deflections of building walls is also applied for measuring floor sloping. The satellite method, where open space is required, is an exception here. An electronic or laser spirit level is widely used. In order to achieve greater accuracy, one can apply a levelling measurement of floors inside the building by placing a levelling rod on the floor, and for ceilings - by applying the rod to the ceiling (so-called measurement of inside diameter of the room).

\subsection{Registration of other structural elements}

For the rectification of multi-floor buildings, it is justified to perform measurements of elevator shafts (if such exist). Practical experience shows that an elevator core construction is made with the highest accuracy and is not subject to modifications during structure operation. Measurement results for floor slopes and wall surface deflections reveal large disparities between particular floors and apartments, mainly due to refurbishments made.

Elevator shaft deflection measurements can be made by means of an optical plummet, with the method of offsets from the measurement plumb line to the core walls. Deflection is measured from the plumb line of each core wall, with measuring at the same time the height of the level at which the measurement was made. Fig. 3 shown below lists results of independent measurements of core deflection in two elevator shafts.

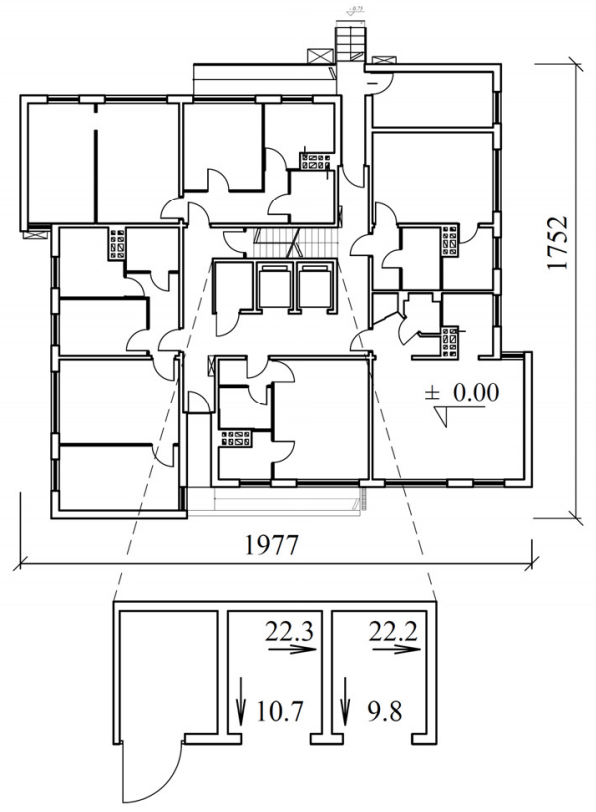

Fig. 3 Floor plan of the repetitive floor with the direction and value of the elevator shaft deflection marked.

Similarly, more modern laser plummets will also find their application here.

The interesting solutions given in [12] show the application of, e.g. digital cameras, sensors measuring length changes and inclinometers, or laser scanning when taking an inventory of mining shafts, which can also be successively used in surface conditions. 


\subsection{Spatial registration of structure $(x, y, z)$}

Methods involving spatial measurement have to be often used for inventory measurements of structures, the purpose of which is to determine their technical condition. A full picture of the deformed structure can be obtained by measuring horizontal and vertical displacements. The most traditional techniques include, in particular, the method of space intersections and the polar method [13] (Fig. 4). Measurements carried out with modern equipment such as a tacheometer enable to make a measurement with appropriate accuracy.

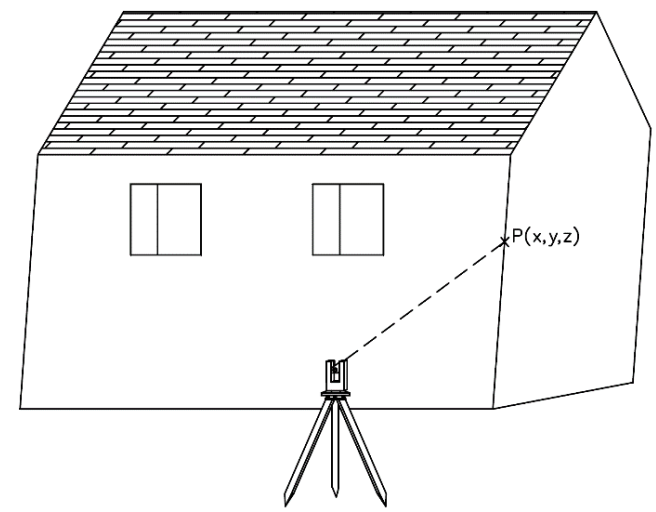

Fig. 4 Spatial registration of the structure $(x, y, z)$

The most modern methods, providing a full picture of the studied structure, include ground laser scanning. An automated tacheometric measurement enables to obtain an immense amount of data such as a cloud of points within short time. Data processing is most work intensive.

Satellite measurements with GNSS systems are also used in displacement measurements. The static method is used most often for ensuring appropriate accuracy, combined with classical methods, in order to make a reference to the global coordinate system. Proper visibility must be ensured for this method, i.e. the horizon cannot be covered, which is most problematic for this method.

The photogrammetrical method consisting of geometrical transformation of photographs is the least accurate method.

Relative displacements and deformations during continuous registration of structure behaviour can be obtained by using such sensors as clinometers, inclinometers, extensometers, etc., classified as telemetric methods.

\section{Terrain sloping measurements}

Land observations can be performed with commonly used geodesical methods.

Measurements of peripheral surveying lines, e.g. with levelling techniques, are performed in order to observe changes in terrain sloping around building structures. A direct terrain measurement, using electronic tachymetry or GPS techniques, allows to observe the occurring horizontal displacements. The photogrammetrical method (by preparing aerial photos or satellite images), aerial laser scanning (so-called LIDAR) or the radar interferometry method - InSAR, have to be applied to produce data for larger areas. 


\section{Examples of observations in scope of deflections of buildings structures and land sloping}

In general, it is assumed that at the stage of forecasting the building deflections, a building deflection corresponds to terrain sloping [1]. Observation results often reveal, however, that differences exist between building deflection and land sloping, which is also presented in this chapter.

The studies were carried out on the land subject to intensive impact of underground mining exploitation. The observations covered the measurement of deflections of 12 buildings carried out with an electronic spirit level for corners of external and internal walls and floors. Fig. 5 below shows an example of measurements prepared in the form of a building view with the deflection values measured.

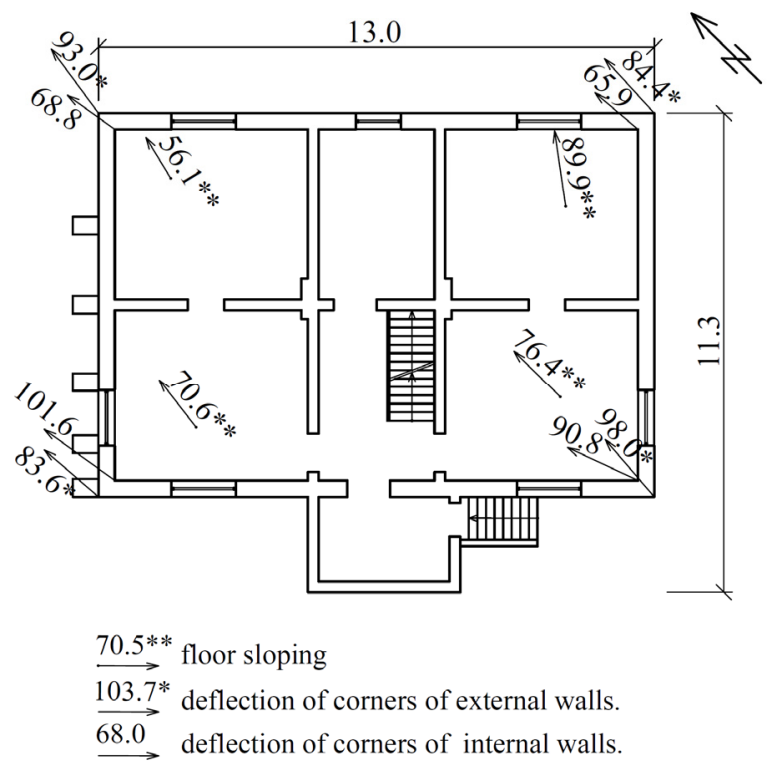

Fig. 5 Example of building view with the measured floor sloping and deflection of corners of external and internal walls.

The deflections measured and forecast terrain slopes are listed below.

Table 1. List of the measured building deflections with calculated terrain deformation indicators for mining exploitation performed.

\begin{tabular}{|c|c|c|c|c|c|c|}
\hline \multirow{2}{*}{ No. } & \multicolumn{3}{|c|}{ Average deflection $[\mathrm{mm} / \mathrm{m}]$} & \multicolumn{3}{|c|}{$\begin{array}{l}\text { Terrain deformation indicators calculated } \\
\text { with programmes of Prof. J. Białek } \\
\text { for exploitation since building construction } \\
\text { to } 10.01 .2017\end{array}$} \\
\hline & \begin{tabular}{|c|}
$\begin{array}{c}\text { Corners of } \\
\text { external } \\
\text { walls }\end{array}$ \\
\end{tabular} & $\begin{array}{l}\text { Corners of } \\
\text { internal } \\
\text { walls }\end{array}$ & Floors & $\begin{array}{l}\text { Sloping } \\
\mathrm{T}[\mathrm{mm} / \mathrm{m}]\end{array}$ & $\begin{array}{l}\text { Horizontal } \\
\text { deflection } \\
\varepsilon[\mathrm{mm} / \mathrm{m}]\end{array}$ & $\begin{array}{l}\text { Curvature } \\
\text { radius } \\
\mathrm{R}[\mathrm{km}]\end{array}$ \\
\hline 1. & 59.2 & 61.5 & 54.2 & 47.6 & -6.3 & 8.5 \\
\hline 2. & 77.0 & 72.9 & 74.3 & 43.9 & -2.8 & 9.5 \\
\hline 3. & 60.5 & - & - & 29.9 & -20.8 & 1.1 \\
\hline
\end{tabular}




\begin{tabular}{|c|c|c|c|c|c|c|}
\hline 4. & 63.3 & 73.6 & 72 & 65.6 & 77.4 & -0.5 \\
\hline 5. & 71.3 & 77.5 & 83.9 & 31.8 & -32.7 & 1.9 \\
\hline 6. & 115.2 & 111.2 & 91.1 & 90.7 & -14.1 & -2.1 \\
\hline 7. & 101 & 99.1 & 99.1 & 107.1 & -37.9 & 1.3 \\
\hline 8. & 89.8 & 81.8 & 73.3 & 44.1 & -41.4 & 0.9 \\
\hline 9. & 92.5 & - & - & 27.1 & -31.5 & 1.7 \\
\hline 10. & 57.8 & 62.4 & 55.3 & 22.8 & 9.8 & -5.6 \\
\hline 11. & 50.3 & 54.9 & 34.7 & 35.7 & 45.3 & -1.2 \\
\hline 12. & 57.8 & 69.3 & 68.1 & 50.7 & -7.3 & -4.7 \\
\hline
\end{tabular}

Differences in results of deflection measurements of inner corners relative to outer corners result principally from the renovations made inside the buildings and from the measurement error due to the fact that the point of applying a spirit level, especially on the strongly deformed walls, was not unambiguously identified. Differences in deflections of particular structural elements also prove the structure's spatial work. This phenomenon is especially visible on areas subject to intensive impacts such as compressive and tensile strains and terrain curvatures. The majority of structures show a higher average deflection than terrain sloping. Apart from the influence of underground mining exploitation, the differentiated morphology of the analysed terrain and the layers deposited in the subsoil in form of silty and sand formations and fine sands with washing ability should be indicated as the cause of the existing phenomenon.

\section{Summary}

The measurements of vertically deflected structures are carried out as part of inventory measurements for control and research purposes, to explain the impact of mining exploitation on the structure, and also when identifying the initial value in the rectification process. The measurement method applied should provide data with adequate accuracy. The buildings subject to mining impacts, especially in the form of deformations and curvatures, exhibit various types of deformations, e.g. form-related deformations of walls. Methods enabling to observe horizontal and vertical displacements should be employed to observe full changes in the coordinates $\mathrm{x}, \mathrm{y}, \mathrm{z}$. The effect of non-mining factors, especially soil conditions and construction errors of the building structure itself, should be taken into account when interpreting the deflection values obtained.

\section{References}

1. M. Kawulok: Evaluation of functional properties of buildings considering mining impacts. Publishing House of the Building Research Institute, Warsaw (2000)

2. W. Mika, L. Muszyński: Assessment of admissible deflections of residential buildings on mining areas considering structural safety. Occupational Safety and Environmental Protection in Mining, 3, 10-15 (2011)

3. K. Gromysz, T. Niemiec: Selected issues in straightening the vertically deflected building structures. 3rd Scientific and Training Conference, Safety and protection of building structures on mining areas, Ustroń-Zawodzie. Scientific works of the Central Mining Institute (GiG), Katowice, 43-65 (2010)

4. PN-81/B-03020 - Foundation bases.

5. T. Niemiec, R. Zaborek: Accuracy in construction of civil structures and accuracy of their rectification. 2nd Conference: Building structures on mining areas. Katowice (2016) 
6. T. Kowal: Proposed determination of the damage value in form of permanent vertical deflection of the building body. Mining Review, 10, 164-169 (2014)

7. M. Kawulok, L. Chomacki, B. Parkasiewicz, L. Słowik: Demolition of 25 residential buildings due to intensive impacts of mining exploitation. 26th Research and Technical Conference "Building Failures". Szczecin (2013)

8. M. Wyleżoł: Determination of measurable deflection of buildings in the aspect of their designing. Introduction to selected issues in civil engineering, scientific works of $\mathrm{PhD}$ students. Publishing House of the Silesian University of Technology, Gliwice, 191-198 (2017)

9. S. Szpetkowski: Deformation measurements on mining areas. Śląskie Publishing House, Katowice (1978)

10. W. Bochenek, Z. Motyka, H. Passia, A. Szade: Laser control of buildings and engineering structures subject to impact of underground mining in the region of the Upper Silesia Coal Basin. Scientific works of the Central Mining Institute (GiG), Katowice (2007)

11. J. Kwiatek at al.: Safety and protection of building structures on mining areas. Publishing House of the Central Mining Institution, Katowice (1997)

12. M. Jabłoński, W. Jaśkowski: Review of shaft pipe inventory-taking techniques. Construction and Architecture, 15(3), 63-74 (2016)

13. 2. J. Ćwierz, W. Cinal, A. Kampczyk: Measurement of building facade walls deflections from the vertical plane. Scientific Journals of the Częstochowa University of Technology, 22 (172), 48-65 (2016)

14. P. Gruchlik: Ground 3D laser scanning, experience and perspectives. Mining Review, 5, 20-25 (2015) [14] 